\begin{tabular}{cccc}
$\begin{array}{c}\text { 第 } 6 \text { 卷第3 } \\
1994 \text { 期 } 9 \text { 月 }\end{array}$ & 湖 泊 科学 & Vol. 6,No.3 \\
\hline
\end{tabular}

\title{
不同养殖类型池塘 浮游生物群落结构的初步分析
}

\author{
谷孝 鸿 \\ (中国科学院本京地理与湖泊研究厉, 南京 210008)
}

\begin{abstract}
提要 1988 年在山东省禹城县渍涝洼地中选择四口鱼䈐以不同放养类型进行试验, 4-10

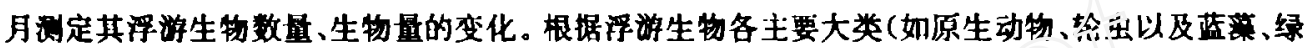

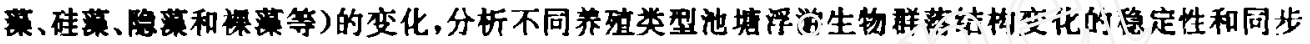

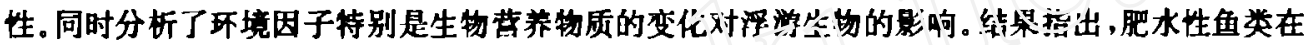

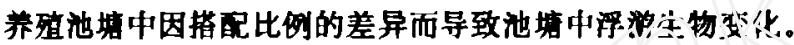

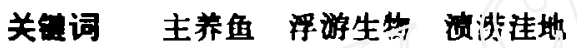

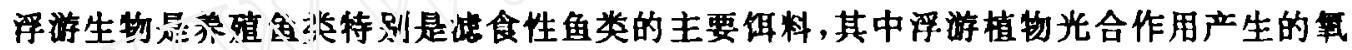

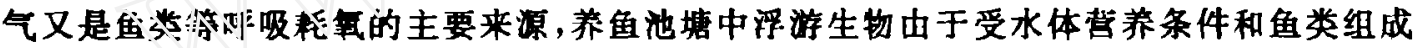
等影响,种粎不断发生变化。1988 年在辛店试验渔场利用盐清港洼地开挖的鱼塘，对相邻池 塘不同养殖类型即以不同鱼类为主养鱼的四口地垢中的浮游生物逐月采样分析，并对不同 养殖类型池塘游生物的变化规律进行研究。

禹城县辛店注是封闭型的由季节腑积水形成的次生盐渍湿洼地,面积 $374.5 \mathrm{hm}^{2}$, 洼底 高程 $17.5 \mathrm{~m}$ (黄海基面), 为全县最低点.洼缘高程 $20.0 \mathrm{~m}$, 高差 $2.5 \mathrm{~m}$ 。由于兴水利,开挖 河道，地下水位抬高，造戍洼地底部泊泽化，高处盐溃化。洼地中土就盐分平均含量为 $4.3 \%$ ， $\mathrm{pH}$ 值为 8.8-9.9。198f 年, 中国科学院南京地理与湖泊研究所对注地进行了综合考察, 根 据用中求治的原则, 采用挖鱼塘、建台田的改造方式,建成了一个洼地生态渔业基地。池塘为 1986、1987 年两年所开挖, 现已发展养殖水面千余亩。养殖用水为引黄水及地下水, 塘水矿 化度在 $0.5-2.2 \mathrm{~g} / \mathrm{L}, \mathrm{pH}$ 值为 $8.35-8.80$ 。

\section{1 条件与方法}

\section{1 试验塔及鲁种放来}

1988 年,在㴔场选择四排相邻的 $1 、 2 、 3 、 4$ 号池塘 (以下写成 4-1、4-2、4-3、4-4) 进行试 验。每口试验塘实际面积约 $3000 \mathrm{~m}^{2}$, 水深 $1.5 \mathrm{~m}$ 左右,长宽比为 $5: 3$, 坡比 $1: 2$, 采用同一

- 国家重点科技攻关顷目 $(75-04-01-01)$ 。

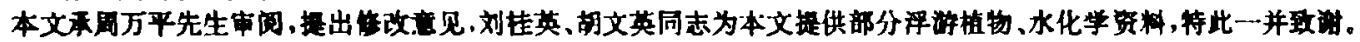
稓日期; 1992 年 8 月 21 日, 接受日期; 1993 年 12 月 1 日。 
方式排薄案水，排灌条件差，没有增氧设施。

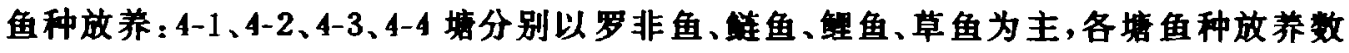
量、搭配比例见表 1。根据不同时期测定出鱼的生长速度并推算鱼类存塘量后, 按一定比例 投饵。经过近 7 个月饲养后,各塘产量分别为 $5955 、 5175 、 4905 、 4425 \mathrm{~kg} / \mathrm{hm}^{2}$ 。

表！不同养殖类型池境鱼种放养情况・

Tab. 1 The survey of fingerling in different types of fish ponds

\begin{tabular}{|c|c|c|c|c|c|c|c|c|c|c|c|c|c|c|c|c|}
\hline \multirow{2}{*}{ 塨号 } & \multicolumn{2}{|c|}{ 罗非鱼 } & \multicolumn{2}{|c|}{ 白 琏 } & \multicolumn{2}{|c|}{ 鱼 } & \multicolumn{2}{|c|}{ 草 鱼 } & \multicolumn{2}{|c|}{ 花 徒 } & \multicolumn{2}{|c|}{ 鱼 } & \multicolumn{2}{|c|}{ 鱼 } & \multicolumn{2}{|c|}{ 合 H } \\
\hline & 属数 & 重量 & 尾数 & 勇兵 & 尾数 & 重量 & 尾数 & 重量 & 屏数 & 重事 & 尾数 & 重量 & 尾数 & 重量 & 尾数 & 重量 \\
\hline 4-1 & 17925 & 103.5 & 2250 & 405 & 1200 & 133.5 & 2670 & 138 & 750 & 127.5 & 375 & 7.5 & 300 & 18 & 25470 & 933 \\
\hline 4-2 & & & 7500 & 607.5 & 1350 & 84 & 2640 & 64.5 & 1230 & 88. 5 & 1350 & 24 & 30 & 16.5 & 14370 & 885 \\
\hline 4-3 & & & 3900 & 282 & 7395 & 511.5 & 3330 & 78 & 900 & 4. 2 & 975 & 24 & 300 & 18 & 16800 & 955. 5 \\
\hline $4-4$ & & & 4800 & 394.5 & 1680 & 99 & 6735 & 312 & 1500 & 60 & 300 & 22.5 & 300 & 19.5 & 15215 & 907.5 \\
\hline
\end{tabular}

*层数以尾 $/ \mathrm{hm}^{2}$ 计, 重量以 $\mathrm{kg} / \mathrm{hm}^{2}$ 计

\section{2 采样与计数}

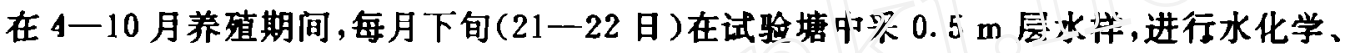

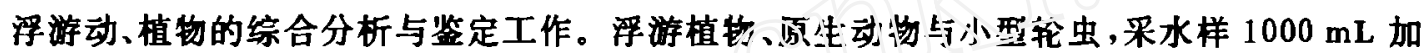

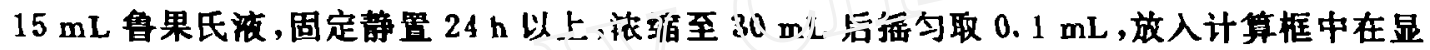

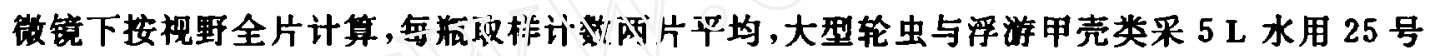

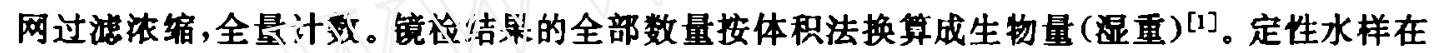
池塘四角措取, 由于浮渄生物在池塘水体中的团块分布及风力影响, 浮游生物的采样受到一 定影响。

\section{2 结 果}

在 4-10 月, 每塘各采水样 7 次, 经定量分析, 各塘浮游植物、浮游动物的年均值列于表 2 , 而鱼塘中浮游植物、浮游动物的主要大类蓝藻、绿落、隐萧、硅荤以及原生动物、轮虫的数 量、生物量逐月变化情况见表 3 ,对于影响浮游植物、浮游动物的鱼塘水体营养物质的变化 情况见表 4。

表 2 不同养殖类型池境浮游生物的年平均值

Tab. 2 The average abundence and biomass of the plankton in different types of fish ponds

\begin{tabular}{|c|c|c|c|c|c|c|}
\hline \multirow{2}{*}{ 萝 } & \multirow{2}{*}{ 号 } & \multicolumn{2}{|c|}{ 㐿 植 物 } & \multicolumn{2}{|c|}{ 洋生动物 } & \multirow{2}{*}{$\begin{array}{l}\text { 动、植物 } \\
\text { 生物五之比 }\end{array}$} \\
\hline & & 数量 $\left(10^{4} \uparrow / L\right)$ & 生物量(mg/L) & 数量 $\left(10^{4} \uparrow / \mathrm{L}\right)$ & 生物量 $(\mathrm{mg} / \mathrm{L})$ & \\
\hline & & 6236.5 & 121.78 & 27603.8 & 4.01 & $1: 30.4$ \\
\hline & & 9144.6 & 108.67 & 25593.5 & 5. 53 & $1: 19.7$ \\
\hline & & 6971.1 & 83. 6 & 25074.2 & 5. 48 & $1: 15.3$ \\
\hline & & 4145. 1 & 72.7 & 39344.7 & 5. 12 & $1: 14.2$ \\
\hline
\end{tabular}

综合表 2 和表 3 可知, 虽然四口鱼塘主养鱼不同,但浮游生物数量变化各塘趋于相同, 游动物中原生动物、轮虫占总游动物生物量四口塘都在 $83 \%$ 及 $16 \%$ 左右,月变化相对 
表 3 不同养殖类型池塔浮斿生物主要大类逐月变化·

Tab. 3 Montbly changes of main population of plankton in different types of the fish ponds

\begin{tabular}{|c|c|c|c|c|c|c|c|c|c|c|c|c|c|c|c|}
\hline \multirow{2}{*}{ 境 } & & \multicolumn{2}{|c|}{ 蓝竟 } & \multicolumn{2}{|l|}{ 娽 } & \multicolumn{2}{|l|}{ 硅 } & \multicolumn{2}{|l|}{ 标 } & \multicolumn{2}{|l|}{ 急 } & \multicolumn{2}{|c|}{ 原生动物 } & \multicolumn{2}{|c|}{ 轮 虫 } \\
\hline & & 数量 & $\%$ & 数量 & $\%$ & 数昔 & $\%$ & 数证 & $\%$ & 数量 & $\%$ & 数量 & $\%$ & 数量 & $\%$ \\
\hline \multirow{7}{*}{ 4-1 } & 48 & 120.88 & 1.27 & 88.36 & 37.48 & 16.73 & 7. 10 & 5.91 & 2.51 & 2.46 & 1.04 & 10800 & 70.5 & 4500 & 29.4 \\
\hline & 5 月 & 100.17 & 20.37 & 290.22 & 59.01 & 74. 1 & 15. 07 & 7. 47 & 3. 55 & 8. 12 & 1.65 & 63000 & 93.7 & 4200 & 6.3 \\
\hline & 6 月 & 5901.96 & 94.65 & 216.57 & 3.47 & 110.34 & 1.77 & 6.15 & 0.10 & 0.82 & 0.01 & 48800 & 75.7 & 15000 & 24.3 \\
\hline & 7 月 & 9155. 25 & 94.62 & 287. 13 & 2. 97 & 217.41 & 2. 25 & 8. 2 & 0.08 & 8. 20 & 0.08 & 10800 & 59.0 & 7500 & 41.0 \\
\hline & 8 月 & 8454.22 & 93.85 & 295. 35 & 3. 28 & 209.2 & 2. 32 & 36.92 & 0.41 & 12. 30 & 0.14 & 4800 & 100.0 & & \\
\hline & 9月 & 7170.3 & 84.16 & 812.19 & 9. 53 & $|496.34|$ & 5.83 & 4. 10 & 0.05 & 36.92 & 0.43 & 5100 & 94.4 & 300 & 5.6 \\
\hline & 10 月 & 6817.53 & 73. 87 & 1870.51 & 20.27 & 529.16 & 5.73 & 8. 20 & 0.09 & 4. 10 & 0.04 & 20400 & 100.0 & & \\
\hline \multirow{7}{*}{$1-2$} & 4月 & 164.17 & 60.03 & 71.64 & 26.20 & 16.25 & 5.94 & 8. 13 & 2.97 & 5.66 & 2.07 & 52800 & 94.0 & 3300 & 5.9 \\
\hline & 5 月 & 298.29 & 46.94 & 246. 12 & 38.73 & 69. 32 & 10.91 & 8. 05 & 2.84 & 3.28 & 0.52 & 3000 & 13.4 & 3900 & 6.3 \\
\hline & 6 月 & 16420.3 & 91.52 & 1205.98 & 6.72 & 283.03 & 1. 58 & 20.51 & 0.11 & 12. 31 & 0.07 & $5370 n$ & 3.5. 6 & 9000 & 14.3 \\
\hline & 7 月 & 3347.23 & 88.03 & 246.12 & 6.47 & 168.18 & 4.42 & 4. 10 & 0.11 & 36.92 & $0.9 \pi$ & 23490 & 75. 7 & 7500 & 24. 2 \\
\hline & 8 月 & 26010.78 & 96.08 & 726.05 & 2.68 & 258.43 & 0.95 & 61. 5? & 0.23 & 16.41 & 0.06 & 2700 & 90.0 & 300 & 10.0 \\
\hline & 9 月 & 7998.9 & 73.78 & 2133.05 & 19.67 & 693.24 & 6. $3^{\circ}$ & 4. 10 & 0. $: 4$ & 12. 31 & $0 .: 1$ & 1500 & 20.8 & 5700 & 79.2 \\
\hline & 10月 & 2514.52 & 72.46 & 754.78 & 21.75 & 176.39 & 5. $n 8$ & (24. 5! & $0.7 \mathrm{i}$ & & & 11700 & 95.1 & 600 & 4.9 \\
\hline \multirow{7}{*}{$1-3$} & 4 月 & 63.01 & 66.32 & 9.34 & 9.83 & 15.75 & 16.58 & 4.68 & 4.93 & 2. 22 & 34 & 15300 & 49.0 & 15900 & 50.9 \\
\hline & 5 月 & 146.03 & 40.78 & $156.6^{\circ}$ & 43.75 & : 8.15 & 10. 05 & i0. 66 & 2.98 & 4. 51 & 1.26 & 6900 & 47.9 & 7500 & 52.0 \\
\hline & 6 月 & 8806.99 & 94 es & 356.137 & 3. 35 & 1.10 .75 & 1.19 & & & & & 48900 & 75.8 & 15600 & 24.2 \\
\hline & 7 月。 & $11552 \leqslant 4$ & 94.95 & 134. 31 & 3. 57 & 106.65 & 0.86 & 16. 41 & 0.13 & 57.43 & 0.47 & 22200 & 79.5 & 5700 & 20.4 \\
\hline & 8 月 & $12 \hat{2} \angle 5.2 S$ & 5.95 & 283.04 & 2.15 & 188.69 & 1. 43 & 53.33 & 0.41 & 8.20 & 0.06 & 7800 & 96.3 & 300 & 3.7 \\
\hline & 9月 & 7666. 54 & 85.62 & 750.66 & 8. 32 & 529.16 & 5.91 & 8. 20 & 0.09 & & & 5400 & 40.0 & 8100 & 60.0 \\
\hline & 10 月 & 3097.0 & 72.18 & 861.42 & 20.08 & 315.86 & 7. $3 \hat{0}$ & 16.41 & 0.38 & & & 15600 & 98.1 & 300 & 1.9 \\
\hline \multirow{7}{*}{-4} & 4 月 & 11.31 & 49.66 & 9706 & 34.43 & 20.67 & 7.26 & 16. 49 & 5.80 & 1.97 & .69 & 48600 & 90.0 & 5400 & 10.0 \\
\hline & 5 月 & 200.58 & 47.57 & 163.25 & 38.72 & 29.12 & 6.91 & 18.04 & 4.28 & 9.43 & 2.24 & 46200 & 80.8 & 10800 & 18.9 \\
\hline & 6 月 & 632.12 & 70.72 & 223. 97 & 25.06 & 23. 79 & 2.66 & 12.72 & 1.42 & 1. 23 & 0.14 & 20400 & 67.3 & 9900 & 32.7 \\
\hline & 7 月 & 5442.35 & 94.52 & 172. 28 & 2.99 & 114.86 & 1.99 & & & 28.71 & 0.50 & 56700 & 92.6 & 4500 & 7. 3 \\
\hline & 8 月 & 8659. 33 & 95.43 & 159. 97 & 1.76 & 201 & 2.22 & 28.71 & 0.32 & 24.61 & 0.27 & 37200 & 96.1 & 1500 & 3. 8 \\
\hline & 9月 & 6194.02 & 88.82 & 434.81 & 6. 24 & 324.06 & 4. 65 & 20.51 & 0.29 & & & 13500 & 77.6 & 3900 & 22.4 \\
\hline & 10月 & 3023. 17 & 79.25 & 500.44 & 13.12 & 262.53 & 6.88 & 20.51 & 0.54 & 8.20 & 0.21 & 16200 & 96.4 & 600 & 3.5 \\
\hline
\end{tabular}

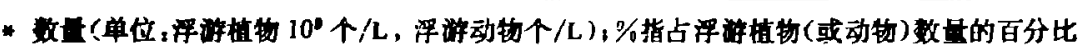

较为平稳, 而浮游植物中蓝、绿落占绝对优势, 四口塔年平均数重占总数量的百分比分别为 $92.69 \% 、 93.01 \% 、 91.76 \% 、 94.38 \%$, 特别是蓝年平均四口塘分别占 $73.26 \%$ 、 $75.55 \%, 78.68 \%, 76.91 \%$, 而在 7.8 月份四口塘蓝㩰均占总数量的 $95 \%$ 左右。因此在高温 季节,一方面高温影响鱼类生长, 另一方面由于蓝荡中有许多为鱼类所不易消化吸收的落类 种群，所以食浮游生物型的鱼类如白鲢等又受食料生物的限制，生长受到影呴。

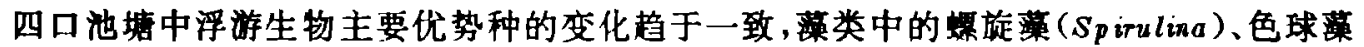

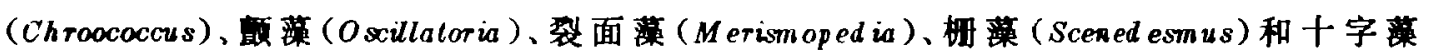
(Crucig enia) 为主。并且各塘出现的季节性优势种也仅为以上这些种类。其数量都在 $21 \times 10^{4}$ 个/L 以上, 最高达 $1000 \times 10^{4}$ 个/L 以上。游动物以砂壳虫 (Diffugia)、焰毛虫 (A stena sia)、似铃壳虫 ( $T$ inlinisop sis)、异尾轮虫 (Trichocerca) 和无柄轮虫 (Ascornorpha) 为主, 同时也出现了其他一些季节性的优势种如急游虫 (Strambilid ium)、楞花辟尾轮虫 (Brachious 
表 41988 年不同类型池塔营羊物质的逐月变化情况

单位:mg/L

Tab. 4 - Monthly changes of nutritional factor in different types of fish ponds

\begin{tabular}{|c|c|c|c|c|c|c|c|c|c|}
\hline 日 榺 & 笛 & TN & $\mathbf{T P}$ & $\mathrm{NO}_{2}-\mathrm{N}$ & $\mathrm{NH}_{\mathbf{3}}-\mathrm{N}$ & NHt-N & POt-P & $\mathrm{SrO}_{2}$ & COD \\
\hline \multirow{4}{*}{$\begin{array}{l}\text { 月 } \\
\mathbf{Q} \\
\text { 日 }\end{array}$} & $4-1$ & 2. 34 & 0.11 & 0.00678 & 0.053 & 0.11 & 0.027 & 2.91 & 5. 51 \\
\hline & $4-2$ & 2. 58 & 0.24 & 0.00678 & 0.053 & 0.07 & 0.061 & 3. 21 & 5. 23 \\
\hline & $4-3$ & 2. 36 & 0.10 & 0.00141 & 0.035 & 0.11 & 0.008 & 1.86 & 1.88 \\
\hline & $4-4$ & 3. 80 & 0.11 & 0.00533 & 0.046 & 0.004 & 0.012 & 2.91 & 4. 00 \\
\hline & 4-1 & 4. 51 & 0.14 & 0.0047 & 0.059 & 0.22 & 0.028 & 3.21 & 5. 17 \\
\hline & $4-2$ & 4.92 & 0.09 & 0.00265 & 0.062 & 1.42 & 0.015 & 6.52 & 6. 50 \\
\hline & 1-3 & 5. 36 & 0.15 & 0.00595 & 0.063 & 0.27 & 0.014 & 4.56 & 6. 31 \\
\hline & $4-4$ & 3. 54 & 0.09 & 0.00636 & 0.070 & 0.44 & 0.028 & 4. 56 & 4. 53 \\
\hline & 4-1 & 4.08 & 0.10 & & 0.03 & 0.47 & 0.034 & 10.23 & 3. 96 \\
\hline & $4-2$ & 4. 70 & 0.19 & & 0.03 & 0.33 & 0.062 & 13.02 & 5. 03 \\
\hline & $4-3$ & 6. 50 & 0.20 & & 0.04 & 0.87 & 0.038 & 9.64 & 5. 17 \\
\hline & $4-4$ & 3. 83 & 0.01 & & 0.02 & a. 36 & 0.044 & $8.3 ?$ & 4.53 \\
\hline \multirow{4}{*}{$\begin{array}{l}\hat{F} \\
\hat{E} \\
E\end{array}$} & $4-1$ & 3. 55 & 0.08 & & 0.02 & 0.07 & 0.02 & 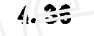 & 4.81 \\
\hline & $4-2$ & 4. 43 & 0.13 & & 0.03 & 1.04 & 0.04 & 11. $3 E$ & 3. 40 \\
\hline & 4-3 & 4. 40 & 0.13 & & 0.03 & c. 12 & 0.02 & 5. 56 & 7.65 \\
\hline & $4-4$ & 4. 04 & 0.09 & & 0. 02 & i & 0.03 & 10.96 & 4. 53 \\
\hline \multirow{4}{*}{$\begin{array}{l}a \\
\xi \\
\vdots \\
a\end{array}$} & $4-1$ & 3. 38 & 0.26 & & 0.0 .1 & 1.53 & 0.02 & 1.86 & 7.08 \\
\hline & $4-2$ & 4. 05 & $0 . \$ \overline{3}$ & & 0.65 & 0.64 & 0.05 & 13. 17 & 7.65 \\
\hline & $4-3$ & 3. & 0.32 & & 0.05 & 1.49 & 0.04 & 12.58 & 9.63 \\
\hline & $4-4$ & 3. 74 & 1.25 & & 0.03 & 1.45 & 0.02 & 5. 09 & 8.07 \\
\hline \multirow{4}{*}{$\begin{array}{l}\text { 筷㨁同朝 } \\
\text { 中平均值 }\end{array}$} & 4-1 & 3. 572 & 6.138 & 0.00574 & 0.0404 & a. 44 & 0.0258 & 4.514 & 5.306 \\
\hline & 4-2 & 4. 136 & a. 214 & 0.00472 & 0.045 & 0.70 & 0.0456 & 9.376 & 5. 562 \\
\hline & 4-3 & 4.496 & 0.18 & 0.00368 & 0.0436 & 0.572 & 0.024 & 7.04 & 6. 128 \\
\hline & $4-4$ & 3. 79 & 0.11 & 0.00585 & 0.0372 & 0.451 & 0.0268 & 6.368 & 5. 132 \\
\hline
\end{tabular}

calyciflorus $)$ 多肢轮虫 $(P$ oly arthra ) 等。总的看来，四口塘优势种的差㫒不明显。

\section{3 i寸 论}

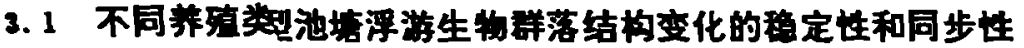

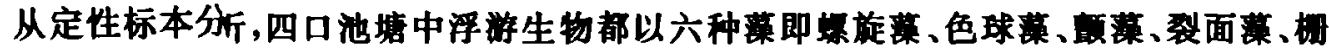
落和十字落和六种游动物即砂壳虫、焰毛虫、似铃壳虫、异尾轮虫、无柄轮虫和多肢轮虫为 优势，在鱼类生长旺期，优势群落在数量和生物量上占绝对优势，相应地其它群落则受抑 制，仅吕很小的比例。此，群落结构的稳定性是这四口鱼㳓浮游生物变化的一个共同特点。 当然，这种相同性与各均引用同一水湶以及用同种饵料喂鱼也有一定关系。在养殖期间优 势群落的数量变化具有|步性,㩰类变化的高峰一般在 7、8、9 月,对于较喜沮的蓝、绿萧,在 一定范围内, 其变化与标变化具有同步性(图 1)。浮动物, 主要是原生动物与轮虫, 其变 化高峰一般在 6-7 月及1月，这说明一级消费者对生产者莒类在食物链中有一定的依赖 性, 但不是绝对依赖, 而浮沄物中的原生动物类在食物链中对细菌等有依椟性, 而对泽游 植物则为非依赖性 ${ }^{[2]}$ 。

养殖期间, 游雚类月鸟数量以肥水鱼为主的 4-2 塘最高, 而以草食性鱼为主的 4-4 


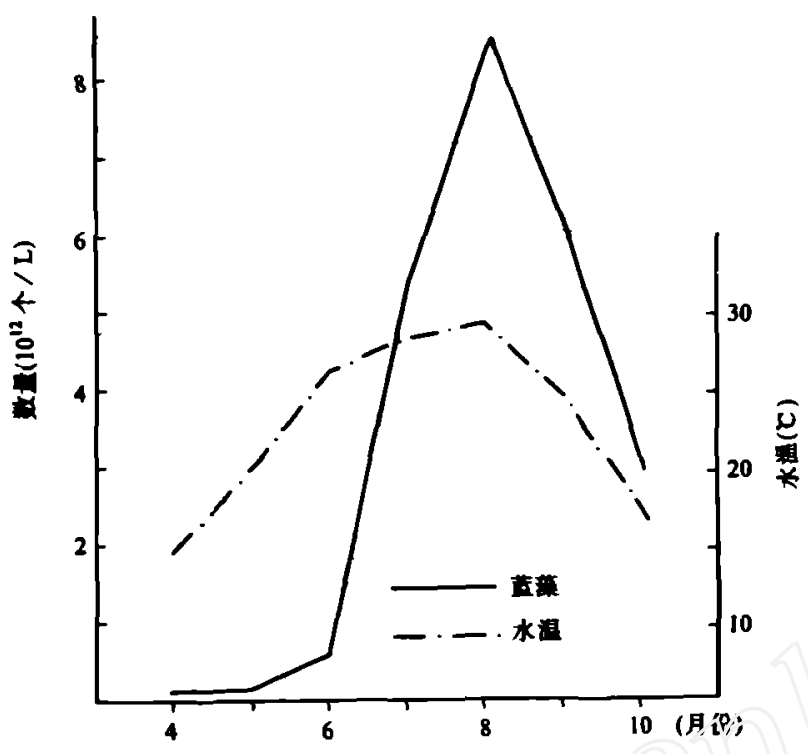

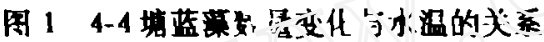

Fig. 1 The celstionsh ps of wate: temperature and the aturulance of cymophyla in No. 4-4 pond

塘只有它的 $1 / 2,4-1 、 4-3$ 塘则介于它 们之间。对浮游动物而言, 则 4-4 为最 高, 为 4-2 的 1.5 倍, 这说明浮游动物 与浮游植物之间变化的抑制性。

从表 3 浮游生物各主要大类的年 变化看出,不同鱼类对浮游生物的利 用程度也不相同。由于浮游生物入体 大小的差异，各塘之间在生物量二的 变化与数量上变化梢有不同。以水 性鱼为主的 4-2 塘远高于以草食主鱼 类为主的 4-4 塘。因此要提高精点池 塘鱼产量,首先要根橴存种养殖自类

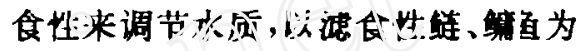
声称售塘，肥水促造桴游生物的贯殖

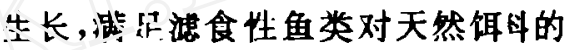
需求，同！鱼类对浮游生物的漕食又 可刺激和促进浮游生物的繁殖生长， 进而起到了调节水体中浮游生勿的密 度动态平衡的作用。对于喜欢清新水 质的草食性鱼类来说，在同等放养量和管理水平相同条件下，与溇食性鱼类相比，游生物 的数量及生物量相应地要低一些。因此, 针对不同养殖鱼类的需要, 科学地调节注塘中浮游 生物群落结构及群体数量, 是提高鱼产量的重要方面。

\section{2 环境因子对浮游生物群落结构的影响}

环境因子对浮游生物群落的影响是多方面的,而且极其错综复杂。试验暏的水温、溶解 氧、pH 值以及生物营养物质等各项数值的高低都对浮游生物的生长、裂殖、样变化起着直 接的作用。从试验塘桴游生物的种类组成来看,生物的多样性远低于其它块的高产塘, 这 与该地区水质盐碃性偏高（一般为 $2 \%$ ，有时也达 $3 \%$ ) 有关, 某些狭盐性的水浮游生物在 这样的环境中较难生存和策行 ${ }^{[3]}$, 但这一共度对鱼的生长謷殖并无影响。召外, 新开鱼塘由 于池塘中有机物积累相对较少, 对生物的多样性也有一定影响。就鱼塘: 体环境而言, 温度 无疑是影响浮游生物种群数量和结构变化的最主要因子之一, 试验结野明, 浮游生物数量 的变化与水温的变化在一定范围内呈正相关 (图 1), 在超过了适宜范劶这种关系又呈负 相关,如 4-2 塘浮游落类在水温 $14.1{ }^{\circ} \mathrm{C}$ 时其数量为 $273.48 \times 10^{4}$ 个牲物量为 11.5334 $\mathrm{mg} / \mathrm{L}$, 但当温度上升到 $28.3^{\circ} \mathrm{C}$ 时, 其数量已达到 $27073.2 \times 10^{4}$ 个 $/ \mathrm{I}$ 生物量达到 282.3903 $\mathrm{mg} / \mathrm{L}$, 当温度超过 $30 \mathrm{C}$ 以上时, 由于浮游荣类的生长、繁殖受到高 量增长速度减缓。

浮游生物在生长策殖过程中除要求一定的适宜温度、光照等件外,适当的水体营养条

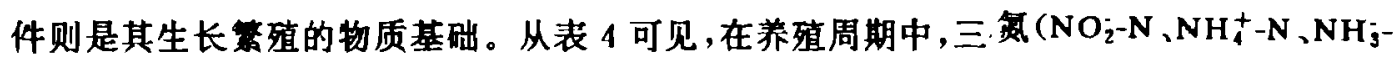
iv) 各塘中的平均数分别为 $0.4861 、 0.7497 、 0.6193$ 和 $0.4940 \mathrm{n} / \mathrm{L}$, 无机磷 (POA4-P)分别为 
$0.0258 、 0.0456 、 0.024$ 和 $0.0268 \mathrm{mg} / \mathrm{L}$, 无机氛和磷的比值分别为 $18.8: 1 、 16.4: 1 、 25.8$ $: 1$ 和 $18.4: 1$ 。这一结果与浮游㩰类对 $\mathbf{N} 、 \mathbf{P}$ 比值的要求 $(7: 1-14: 1)$ 相比较, 差别不太

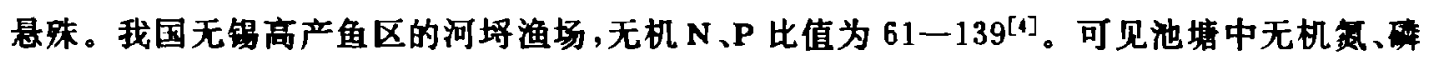
含量越高, 其 N、P 比值越接近于浮游藻类适宜生长繁殖的要求, 游落类数量增长越块。反 之,氞和磷中某一种相对量不足,都会使它种成为生理上的多余,同时全部营养的利用也受 到限制。试验塘水体严重缺惑、缺磷，在二年的养殖过程中虽经施肥等措施现已改善了很多，

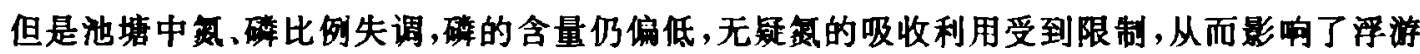

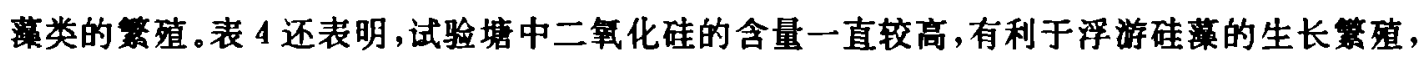
因此,塘内硅落数量仅次于蓝落和绿藻,居第 3 位,为波食性鱼类提供较好的佴料,这在其它 地区的养鱼池塘中不易多见。再从浮游动物和浮游落类生物量的比值来看,四口塘分别为 1 : 30.4、1: 19.7、1: 15.3 和 1: 14.2, 而一般高产鱼塘浮游动物和浮游植物生物量比为 1 : 3 左右 ${ }^{[5]}$, 显然浮游动物生物量低于浮游㩰类,其原因主要是该试验塔开挖不久, 塘内适

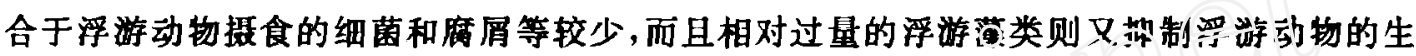

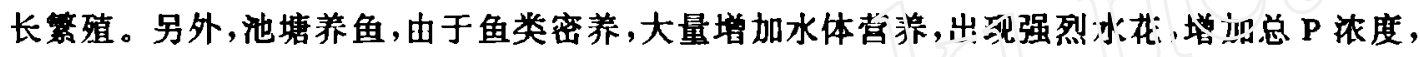

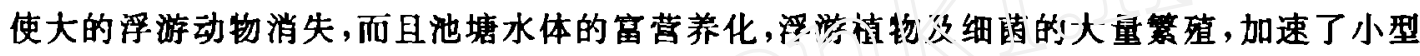
的原生动物的代谢、生长和繁殖，但游动物社数量和生海量亡都远低于浮游藻类。

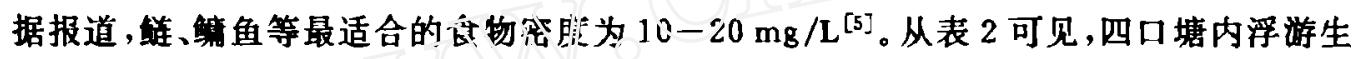
物的生物量都高于这一值、而且就易于为鱼类所消化吸收的硅滺、隐藻的变化来看(表

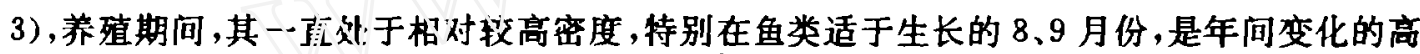
峰。因此,就总体们言,这样的生物密度完全满足涟、解等鱼类的滤食要求。

从四口塘不同的羞殖类型看出, 以肥水性鱼类(涟)为主的滤食游生物的塘放养密度 增大, 浮游植物的初级产量并末下降, 而且搭知比例大的 4-2 塘浮游植物数量却远高于搭的 比例小的。在较浅的池塘 (水深一般在 $1.4-1.6 \mathrm{~m}$ ) 中, 白琏的放养比例加大,加速了水体营

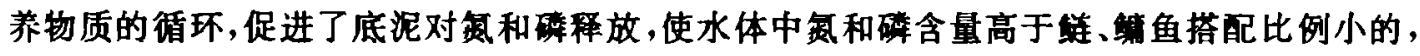
从而促进了孚游植物的大量繁殖，加速了水体营养物质的进程，但在这种密度情况下，如何 提高浮游动物特别是大型的技角类、桡足类数量和生物量,有待今后进一步深入研究。

\section{考文献}

1 何志梅。煌水浮游生物的生物量。动物学杂志, $1979,(4)$.

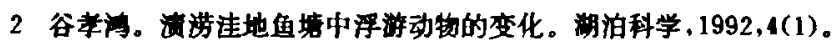

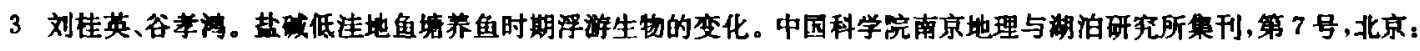
科学出版社, 1990 。

4 雷行之等。无场市河挥口高产鱼池水质研究。水产学报, 1983,7(3)。

5 何志砵、李水函。清河水库的浮游生物。水生生物学集刊, 1983,8 (1)。 


\title{
PRELIMINARY ANAL YSIS ON THE COMMUNITY STRUCTURE OF THE PLANKTON IN DIFFERENT TYPES OF FISH PONDS
}

\author{
Gu Xiaohong
}

(Nanjug Institute of Geography and Limnology, Chines Acad emy of Saiences, Nanjug 210008)

\section{Abstract}

In 1988 , four clossed fish ponds $(4-1,4-2,4-3,4-4)$ were selected to study the different types of main cultivated fingerlings in fish ponds in the saline-alkali watland in Yucheng County of Shandong Province. In pond 4-1, 4-2, 4-3, 4-4, Oreacheris aureus, Hypophthalmichthys molitrix, Cyprimus carpio, Ciexppharyngadon ileilus are the main cultivated fishes, respectively.

During 4-10 months, the ahuidance, bijuss: and the key environmental factors in the four fish ponds were testeo. A crocrling to the changes in the major population of plankton, such as Protiza, Roiilerz, Cyanophyta, Chlorophyta, Bacillariophyta, Cryptophyta and Euglenophyta, the steady and synchronous characteristics of the plankton in four different types of the fish ponds were analysed. In addition, the relationship between the environmental faotor, especially the nutritional factor, and the plankton were studied. As the growth and reproduction of plankton need an abundant nitrogen and phosphorus, there was a proportion suitable to $\mathbf{N}$ and $\mathbf{P}$ of about $15-30: 1$. During the cultivation period, the abundance of plankton had a positive interrelation with water temperature, but the water temperature reached an appropriate point, showing negative interrelation. The different proportions of the ferite feeding fish in ponds led to different species of plankton. In the pond of main cultivated $H$ y pophthalmichthys molitrix, the primary productivity is not on the decline. In favourable conditions, there would be more abundance of plankton.

Key Words Main cultivated fish, plankton, saline-alkali wetland 